\title{
Sample duration and type of stimuli in delayed matching-to-sample in rhesus monkeys
}

\author{
JAMES V. DEVINE, LUTHER C. JONES, JANICE W. NEVILLE, and DILYS J. SAKAI \\ The University of Texas at El Paso, El Paso, Texas 79968
}

\begin{abstract}
Two experiments were performed to determine the effect of sample duration $(0.1,2$, and $4 \mathrm{sec})$, delay interval $(.03,4,8,16$, and $32 \mathrm{sec}$ ), and type of stimulus (color and shape) on the matching performance of rhesus monkeys. In Experiment 1, the 15 possible delay-duration combinations were randomly presented in blocks of 15 trials. In Experiment 2, each duration was held constant and the five delays randomly presented. Then each delay interval was held constant with the three durations randomly varied. Matching performance increased as sample duration increased (ps $<.01$ and .005 ), while length of delay did not significantly affect performance. The type of stimuli paired in the matching test significantly affected performance (ps $<.05$ and .10$)$ with the shape/shape choices leading to the poorest performance. Stimulus discriminability and amount of training with brief sample durations were implicated as significant determinants of matching performance.
\end{abstract}

In recent years, the delayed matching-to-sample (DMTS) task has been used extensively in nonhuman primate memory research. The wide use of the DMTS task to study animal memory is partially due to the noted similarities in task requirements between it and the short-term memory (STM) paradigm used with humans (e.g., Peterson \& Peterson, 1959). Also, the effects of amount of interpolated activity, repetition of the stimulus, and stimulus difficulty in the DMTS tasks are generally similar to the effects of these variables on human STM (Jarrard \& Moise, 1971). However, neither the animal DMTS nor the human STM literature has been consistent in reports of the effects of stimulus duration. A major aim of the present study was to investigate the relationship between stimulus presentation time and the degree of retention using a DMTS paradigm.

The initial task of the subject in a STM experiment most likely involves the perceptual processes of identification or encoding of a stimulus item. Thus, temporal factors in the perceptual stage should strongly influence STM recall accuracy. That is, decreases in stimulus duration should restrict the time for perception and result in poorer recall. Although Aaronson (1967) concluded from her review of the human literature that the time interval between stimuli was more important in STM than stimulus duration per se, her conclusion has not

This research was supported in part by grants to the senior author from the University of Texas at El Paso Research Institute and an equipment loan from the Albany Medical College, Holloman AFB, New Mexico. Requests for reprints should be sent to James V. Devine, Department of Psychology, University of Texas at El Paso, El Paso, Texas 79968. L. C. Jones is now at the University of New South Wales, Kensington, N.S.W., Australia, and D. J. Sakai is now at the University of California at Davis. always been supported (e.g., Potter \& Levy, 1969; Shaffer \& Shiffrin, 1972). In these two studies, recognition memory for complex nonverbal stimuli (pictures of scenes, objects, and people) increased as stimulus duration time increased.

Although simple duration may be readily controlled in a DMTS task, the typical procedure has been to require an observing response to the sample in order to terminate it (e.g., Etkins \& D’Amato, 1969; Jarrard \& Moise, 1971; Mello, 1971). Recently, D'Amato and Worsham (1972) published the first nonhuman primate DMTS study in which sample duration was systematically varied. They used a relatively narrow range of sample durations of $.075, .150$, and $.450 \mathrm{sec}$ and a relatively broad range of delays from 7.5 to $240 \mathrm{sec}$. Contrary to the notion that restrictions in time for perception (decreasing sample duration) lead to poorer retention, they reported that correct recognition was independent of sample duration. However, a study by Jarrard and Moise (1971) suggests that the D'Amato and Worsham results may be limited to the narrow range of sample durations used in their study. Jarrard and Moise used five delay periods $(0,5,15,30$, and $60 \mathrm{sec})$ orthogonally presented with one, two, and four repetitions of the sample stimulus in a DMTS task with stump-tailed macaques. In the repetition conditions, the sample was turned off for $.5 \mathrm{sec}$ following an overt response to it and then presented for $1.5 \mathrm{sec}$ or until the subject pressed the sample again. Performance in the four-repetition condition was superior to that in the two- and one-repetition conditions over all delay intervals, and the two-repetition condition was superior to the one-repetition condition. If consecutive repetitions of the sample stimulus are considered to be functionally equivalent to longer durations, the Jarrard and Moise study may be taken as indirect 
evidence for duration effects in a nonhuman primate memory task. Additional data supporting sample duration effects in a DMTS task have been provided by experiments with pigeon subjects (Maki \& Leith, 1973; Roberts \& Grant, 1974).

Thus, there are conflicting data concerning the effect of sample duration on matching performance with nonhuman primates. However, in terms of cumulative sample time, the Jarrard and Moise animals were exposed to the sample for a much longer duration than D'Amato and Worsham's longest .450-sec duration. In addition, the variation in sample duration in the Jarrard and Moise study is indirect and is confounded with number of presentations. The primary purpose of our study was to determine the effects of controlled sample durations in a DMTS task with exposure times that corresponded closely to those used by Jarrard and Moise. In the first experiment, sample duration and delay intervals were randomly varied in the DMTS paradigm.

\section{EXPERIMENT 1}

\section{Method}

Subjects. Two adult male and one adult female rhesus monkeys (Macaca mulatta), weighing 5.0 to $7.5 \mathrm{~kg}$ at the beginning of the experiment, were used as subjects. They were maintained at $85 \%$ to $90 \%$ of their preexperimental body weight throughout the experiment by supplementing the food reward $(190-\mathrm{mg}$ Noyes banana pellets) with fruit and monkey chow. One of the males had been trained on a matching-to-successive samples task (Devine \& Jones, 1975), while the remaining two animals were experimentally naive.

Apparatus. The subjects were unrestrained during tests in a large primate test chamber similar to that used by Rohles (1961) with chimpanzees. The steel framed chamber, measuring $.914 \mathrm{~m}$ long, $.762 \mathrm{~m}$ wide, and $1.524 \mathrm{~m}$ high, contained a grid floor covered with $3 / 4$-in. plywood. The chamber was equipped with a ventilator, which remained on during testing, and with an overhead light which was off during testing. The two Plexiglas walls of the test chamber were covered with construction paper to minimize visual distraction. Entrance into the chamber was provided by a guillotine door in the third wall. Positioned on the fourth wall was a Foringer stimulus display panel consisting of 12 in-line digital displays horizontal with the floor and a sample display that was $68 \mathrm{~mm}$ above the sixth display. The displays were designed to project stimuli from behind Plexiglas disks $(38.10 \mathrm{~mm}$ in diameter and $25.4 \mathrm{~mm}$ apart). Microswitches recorded and defined a response when one of the 12 comparison disks was pressed. Responses to the sample disk did not activate the recording or programing equipment. Only 2 of the 12 comparison disks, i.e., 5 th and 6th from the subject's left, were used. To the left and below the stimulus panel was a foodwell attached to a pellet dispenser on the outside of the chamber.

The entire display system and feeder were programmed by a HERCO Matching-to-Successive Samples Device (a system custom made by Houston Engineering and Research $\mathrm{Co}$.) in conjunction with a Friden tape-driven programmatic Flexowriter. Program tapes controlled stimulus presentation and position. The Flexowriter typed the trial number, stimulus position ( 5 and 6$)$, and the stimuli within position at the beginning of each trial, and recorded the subject's response by position. Observation of the animals indicated that the $7 \mathrm{sec}$ of typing by the Flexowriter preceding each sample presentation acted as an auditory cue to begin attending to the sample disk. The HERCO console housed four programmable event timers. Two of the timers determined the intertrial interval (ITI) following a correct or incorrect response and were fixed throughout the experiment. The sample duration and delay interval timers consisted of a three-turn dial and a three-position multiplier switch for setting intervals to values in the range of .03 to $33.0 \mathrm{sec}$. Both timers were changed by the experimenter during the ITI according to a predetermined schedule of sample duration and delay intervals.

Stimuli. Ten two-dimensional stimuli were used: five solid white shapes on black background (triange, $X$, square, horizontal line, and vertical line) and five colors that covered the entire response disk (red, green, blue, yellow, and white). The possible combinations of the stimuli were balanced for equal presentation of a color with a color (CC), a shape with a shape (SS), a shape with a color as the distractor (SC), and a color with a shape as the distractor (CS). All stimuli were presented equally often as samples, distractors, left choices (Position 5), and right choices (Position 6).

Procedure. The two naive monkeys were given 4 days of adaptation, response disk pressing, and food magazine training. Following the adaptation training, a sample stimulus was exposed for $10 \mathrm{sec}$, followed within $30 \mathrm{msec}$ by the same stimulus in one of the two response disks. Responses to the lit choice disks were reinforced, whereas responses to an uniit choice disk aborted the trial. An ITI of $12 \mathrm{sec}$ was used during the training phase. Sample exposure time was gradually decreased to $1 \mathrm{sec}$, and the subjects continued training until they responded within $2 \mathrm{sec}$ to the correct choice disk. The animals were placed in the apparatus for $30 \mathrm{~min}$ or for 60 trials, whichever came first. The one sample with one choice training required approximately 7 to 10 days.

The one sample with two choices matching was initiated with a 10-sec sample exposure. The separation between the sample and choices was $30 \mathrm{msec}$ and the ITI was $20 \mathrm{sec}$. The sample exposure was gradually decreased to $1 \mathrm{sec}$ using a $3: 3$ titration procedure (i.e., three consecutive correct responses to decrease exposure time $1 \mathrm{sec}$ and three consecutive incorrect responses to increase exposure time $1 \mathrm{sec}$ ). During this training phase, a correction procedure was introduced (repetition of an incorrect trial). Approximately 25 to 28 days of 40 to 60 trials/day were devoted to the titration of sample duration and the correction procedure. The experienced animal's training began with the 1-sec sample exposure. All subjects were trained on the one sample with two choices task until they responded at $90 \%$ correct for two consecutive days of 60 trials/day.

Upon reaching criterion, the subjects were given 2 days of titrated sample duration training. The titration training began each day at a 1-sec sample exposure and continued until the subject was matching correctly with a $.07-\mathrm{sec}$ or less exposure time. (A 3:2 titration procedure with a .1-sec increment was used until a .1-sec exposure time was achieved, then the increment was $.01 \mathrm{sec})$. On the following day, the three durations used in the study were presented in random blocks of 15 trials for a total of 60 trials. Then titration training with delays was given for 2 days of 60 trials/day. The titration schedule was $3: 2$ with a 2.5-sec increment, and training began each day at a .03-sec delay interval. The sample duration and ITI were 1 and $20 \mathrm{sec}$, respectively, during the delay interval titration training.

Finally, a performance baseline was established using a 1-sec duration, .03-sec delay and a 20-sec ITI for 60 trials daily. Criterion for proceeding to the experiment was $90 \%$ correct choices for 2 consecutive days.

Design. Five delays $(.03,4,8,16$, and $32 \mathrm{sec})$ were orthogonally combined with three durations $(0.1,2$, and $4 \mathrm{sec})$ to yield 15 delay-duration combinations. During the 60 trials/day, each delay-duration combination appeared once every 15 trials, its order determined by random permutations of 15 . The delayduration combinations and stimulus pairs were arranged so that there was one each of CC, CS, SC, and SS trials daily with each of the 15 combinations. Twelve different punched tapes of 60 trials each were used in the experiment. Each duration-delay-stimulus pair combination was presented 24 times to each subject over the 24 days of testing. 


\section{Results}

All three monkeys achieved the performance criterion of $90 \%$ correct choices for 2 consecutive days and each animal completed 1,440 DMTS test trials. The experienced subject required 1,200 retraining trials to meet the performance criterion, while one of the inexperienced subjects required 2,800 and the other 3,600 training trials.

Percent correct performance as a function of the five delays is shown in the upper (experienced subject) and lower (inexperienced subjects) portions of Figure 1 for each of the sample durations. Duration clearly had an effect on the matching performance of the experienced and the inexperienced subjects, with performance poorest at the $0.1-\mathrm{sec}$ duration. The combined data from the three subjects showed that overall percent correct responses increased from $66.5 \%$ at $0.1 \mathrm{sec}$ to $79.7 \%$ at $2 \mathrm{sec}$ and $81.6 \%$ at the $4 \mathrm{sec}$ duration, $F(2,4)=25.36$, $\mathrm{p}<.01$. Performance at the $0.1-\mathrm{sec}$ duration was the primary contributor to the overall significant duration effect, as it differed significantly from the 2 - and 4-sec conditions, ts $(2)=3.00$ and 3.46 , respectively, ps $<.01$. The 2 -sec condition did not differ significantly from the 4-sec condition $(p>.10)$.

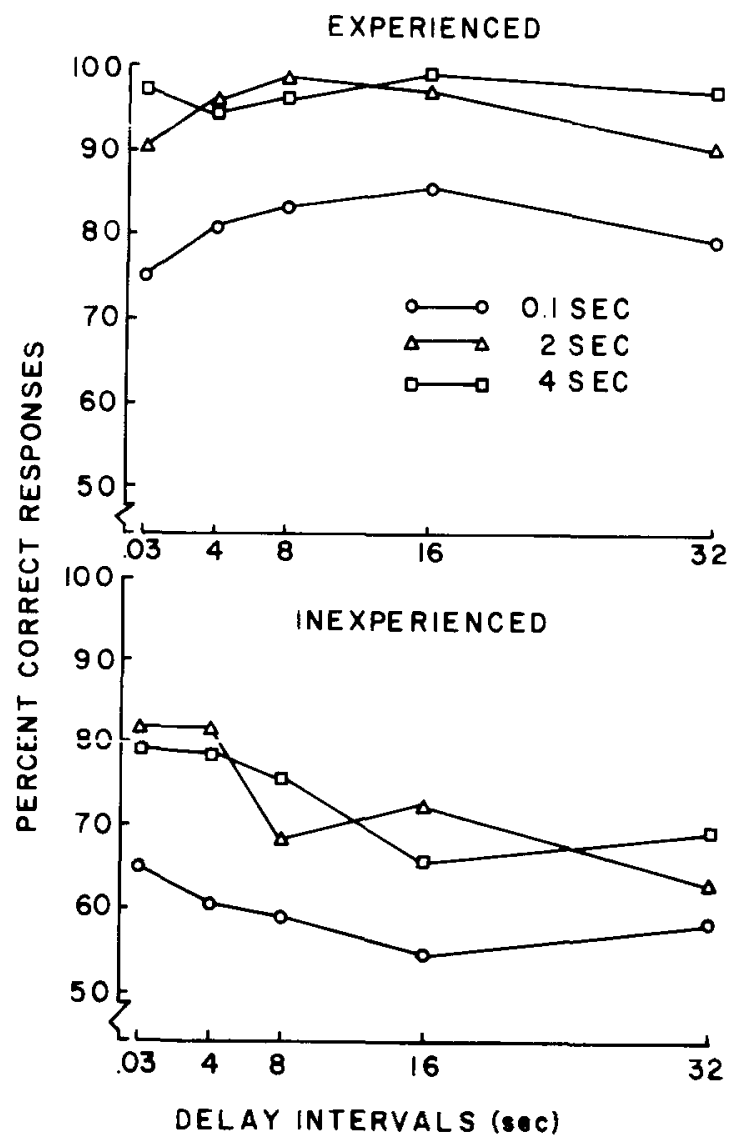

Figure 1. Percent correct responses in Experiment 1 for the sample durations as a function of delay intervals for the experienced subject (upper half) and the two inexperienced subjects (lower half).

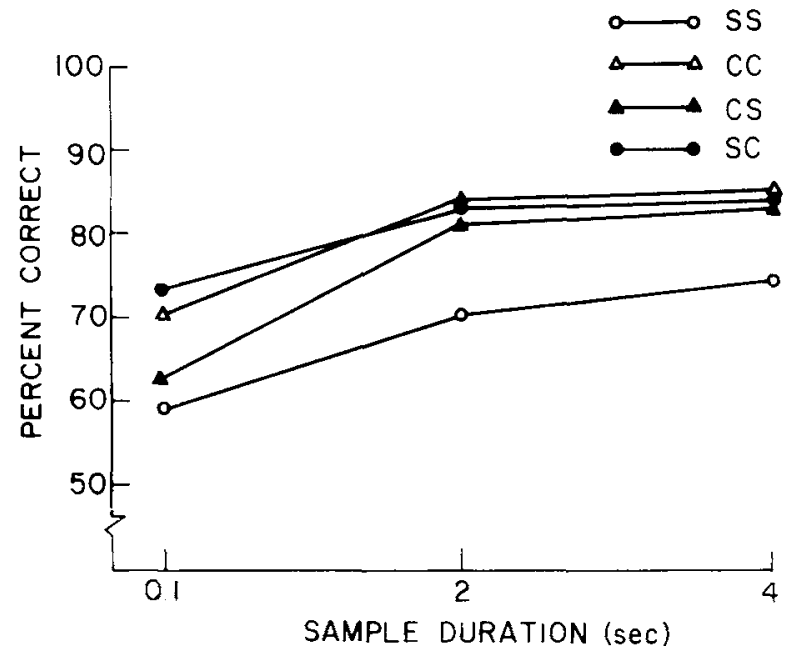

Figure 2. Percent correct responses for the four possible stimulus combinations as a function of sample durations for Experiment 1 ( $\mathrm{S}=$ shape, $\mathrm{C}=$ color ).

Although overall matching performance decreased from $79.6 \%$ to $71.6 \%$ as the delay interval increased, the effect of delay interval was not significant, $F(4,8)=1.44, p>.10$. However, as illustrated in Figure 1, there were marked differences in subjects' performance in the delay conditions, with the experienced subject showing no change from .03 (87.2\% correct) to $32 \mathrm{sec}(87.8 \%$ correct), while the less experienced subjects showed a combined decrease from $75.7 \%$ correct at $.03 \mathrm{sec}$ to $63.5 \%$ correct at the 32-sec delay.

Percent correct performance as a function of duration is shown in Figure 2 for each of the possible stimulus pairings. The type of choice stimulus pairing had a significant effect on matching performance, $F(3,6)=4.96, p<.05$, with the SS choices leading to the poorest performance. Matching with the SS pairs was significantly poorer than with the $\mathrm{CC}$ and $\mathrm{SC}$ pairs, $\operatorname{ts}(2)=2.92$ and 2.18 , respectively, ps $<.01$, but did not differ from performance with the CS pairs. None of the other stimulus pairs differed, and none of the interactions was significant.

\section{EXPERIMENT 2}

The results of Experiment 1 were contrary to the D'Amato and Worsham study in which matching performance was found to be independent of sample duration. In Experiment 1, durations were randomly manipulated with delays, whereas D'Amato and Worsham held sample duration constant for five successive sessions at each delay interval. Thus, the duration effect of Experiment 1 may have been due to the subject's difficulties with constantly shifting duration-delay combinations. In Experiment 2, sample duration was held constant and the delay intervals were randomly presented, then the delay was held constant and tested with durations 
randomly varied. By avoiding the confounding of continued duration-delay interval shifts, the procedure was more comparable to that used by D'Amato and Worsham.

\section{Method}

Subjects, Apparatus, and Stimuli. The two male subjects from Experiment 1 were used. Both the apparatus and the stimuli were the same as those used in Experiment 1.

Procedure. Approximately 1 month of free feeding and no testing elapsed between Experiment 1 and the beginning of Experiment 2. The monkeys were then retrained on the one sample with two choices matching task with a 1-sec duration, .03-sec delay interval, and 20-sec ITI. Retraining was continued to a baseline performance criterion of $90 \%$ correct for 2 consecutive days.

Design. Each sample duration of $0.1,2$, and $4 \mathrm{sec}$ was used for 4 consecutive days with the five delays $(.03,4,8,16$, and $32 \mathrm{sec}$ ) presented randomly within the 60 trials/day. Then, each delay was used for 2 consecutive days of 72 trials/day with the three durations randomly presented within each session. The stimulus pairs were balanced for equal presentation within the 15 possible duration-delay combinations. The total design gave the same number of trials per duration-delay-stimulus pair combination as Experiment 1.

During the 6 weeks of the experiment, the subjects were tested 5 consecutive days each week. The first day of each week was devoted to baseline testing with a 1-sec sample duration, .03-sec delay interval, and 20-sec ITI. The baseline testing was used to verify that the previous week's DMTS testing and/or the 2 days without testing had not changed the animals' baseline matching performance. The monkeys consistently gave $90 \%$ correct or better performance in the baseline testing condition throughout the experiment. The order of testing of constant durations for one subject was 2,4 , and $0.1 \mathrm{sec}$ and $4, .03,8,32$, and $16 \mathrm{sec}$ for the constant delays. The other subject followed the order of $0.1,2$, and $4 \mathrm{sec}$ with the constant durations and $4,16,32, .03$, and $8 \mathrm{sec}$ with the constant delays.

\section{Results}

The results for the 15 duration-delay combinations of the constant duration condition were highly correlated (rho $=.871$ ) with the results of the constant delay conditions; thus the data from the two conditions were combined for the final analysis. The performance of the less experienced subject increased from $67.08 \%$ total correct in Experiment 1 to $74.25 \%$ total correct responses in Experiment 2, while the experienced subject showed a slight overall decrease in percent correct matching $(89.93 \%$ in Experiment 1 to $87.08 \%$ in Experiment 2). However, the results of Experiment 2 (see Figure 3) were essentially the same as those obtained in Experiment 1: the effect of duration was significant, $\mathrm{F}(2,2)=432.86, \mathrm{p}<.005$, with the $0.1-\mathrm{sec}$ condition performance reliably poorer than that of the 2 - and 4-sec conditions ( $p s<.025$ ), and delay interval did not significantly influence matching performance, $F(4,4)=1.93, p>.10$. The overall effect of stimulus combination was marginal, $F(3,3)=7.12, p<.10$, but the individual comparisons revealed the same differences as those reported in Experiment 1 with the performance on SS pairs

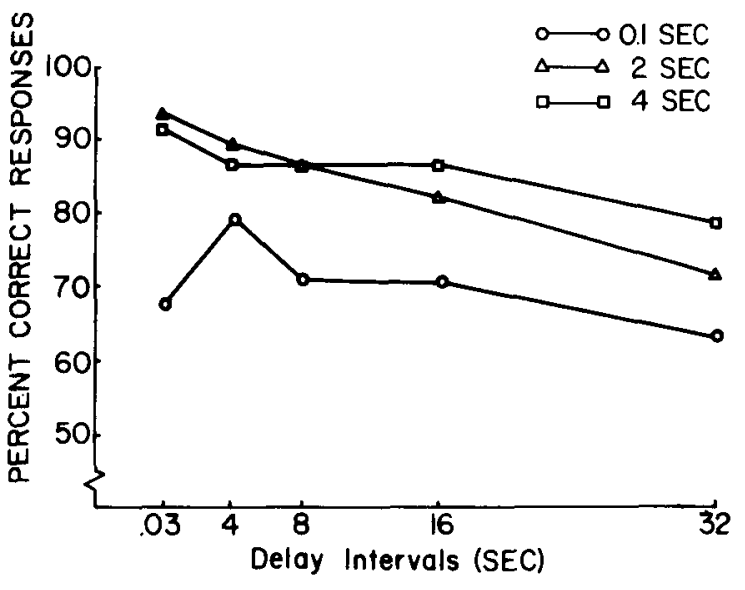

Figure 3. Percent correct responses for the sample durations as a function of delay intervals for Experiment 2.

poorer than that on $\mathrm{CC}$ and SC pairs (ps $<.025$ ), but not significantly different from CS pairs performance $(p>.10)$.

There was considerable variation between stimulus pairs and durations, with performance on CS pairs below that with SS pairs at the 0.1 -sec duration, but the same as the SC and CC pairs at the 2- and 4-sec durations. This led to a significant Stimulus Combination by Duration interaction, $F(6,6)=28.54$, $\mathrm{p}<.001$. None of the other interactions was significant.

\section{DISCUSSION}

The results of Experiments 1 and 2 supported the hypothesis that sample duration may be an important variable in DMTS performance. The effect of sample duration, i.e., the longer the sample duration the better the performance, was robust; it was found when both durations and delays were randomly manipulated, when duration was held constant and delays varied, and when delay was held constant and durations varied.

The dependence of matching performance upon sample duration is consistent with picture recognition studies with humans (Potter \& Levy, 1969; Shaffer \& Shiffrin, 1972) and DMTS studies with several species. For example, the matching performance of pigeons has been found to increase as sample duration increases (Maki \& Leith, 1973; Roberts \& Grant, 1974). Herman and Gordon (1974) reported that when sample duration was decreased from 2.5- to 0.2 -sec, matching performance of the bottlenose dolphin dropped to chance level on an auditory DMTS task. Recently Herzog, Grant, and Roberts (Note 1) found that the matching performance of a stump-tailed macaque and three squirrel monkeys was poorer at 0.5 -sec sample duration than at durations of $2.5,5$, and $10 \mathrm{sec}$. However, the finding of 
a significant effect of sample duration is not consistent with the D'Amato and Worsham DMTS study with cebus monkeys.

D'Amato (1973) has suggested that sample duration will effect STM only when visual materials are unfamiliar and there is opportunity for visual learning. This conclusion was based on the fact that the D'Amato and Worsham animals had extensive DMTS training prior to their duration experiment, one animal having had over 30,000 DMTS trials. The present data suggest that this explanation is not sufficient. The experienced monkey in our study had been trained on various matching tasks and had received approximately 12,000 training trials with the 10 stimuli used in our study. Note, however, that our experienced subject showed the same sample duration effect as the inexperienced animals, but with a higher percentage of correct responses at each duration. Over the five delays of Experiment 1, the experienced subject's performance increased from $80.4 \%$ at the 0.1 -sec duration to $93.3 \%$ at the 2 -sec and $96.0 \%$ at the 4 -sec durations.

An alternative to the stimulus familiarity hypothesis concerns the degree of matching experience with brief sample durations. In addition to differences in stimulus familiarity training, our animals differed from D'Amato and Worsham's in the amount of training with brief sample durations prior to the main experiments. D'Amato and Worsham gave their animals extensive pretraining (over 1,200 trials) with a brief 0.2 -sec sample duration. Then they introduced the sample durations $(.15, .10$, and $.075 \mathrm{sec}$ ) used in the main experiment. Our animals received 2 days (approximately 120 trials) of titrated durations beginning at $1 \mathrm{sec}$ and culminating at $.07 \mathrm{sec}$ and 1 day ( 60 trials) in which the three durations $(0.1,2$, and $4 \mathrm{sec})$ were randomly presented. The Herzog et al. animals were also given limited sample duration experience (approximately 240 trials at each of their durations of $0.5,2.5,5$, and $10 \mathrm{sec}$ ) prior to the test for sample duration effects. Thus, data from the Herzog et al. and the present study suggest that both stimulus familiarity and training with brief sample durations are important factors in determining sample duration effects in DMTS tasks. It is well known that monkeys' DMTS performance benefits greatly from practice, i.e., that monkeys learn to remember (D'Amato, 1973). It is not inconsistent, then, to suggest that monkeys learn to rapidly encode stimuli. That is, given practice with brief sample durations, monkeys learn to attend to and rapidly encode salient features of a stimulus. This is precisely what D'Amato and Worsham have shown, while the present study and Herzog et al. indicate that, without extensive training to encode rapidly, sample duration will influence DMTS performance.

In the present study, it is not clear whether in- creases in sample duration increase performance because the animal may select more salient cues with longer exposures or because the subject is more likely to attend to the sample as duration increases. In our studies, an auditory cue of $7 \mathrm{sec}$ duration acted to prepare the monkeys for sample onset. In Herzog et al., on the other hand, sample presentation was initiated by 10 presses to the sample disk. Obviously, neither an auditory cue nor an overt response assures attention to the sample, and it is possible that the subjects in both studies failed to attend to the sample at short durations. However, if the animals were failing to attend to the sample at short durations, stimulus pairings should not differentially affect performance. That is, errors due to a failure to attend should be fairly evenly distributed over all stimulus choice categories. The monkeys in our study and in the Herzog et al. study showed greater difficulty in matching shape/shape choices than color/color choices, thus suggesting that the animals were looking at the sample but that sample duration was too short for complete encoding.

Stimulus discriminability has received ample documentation as a prominent variable in nonhuman primate discrimination tasks (e.g., Devine, 1970; Draper, 1965; Warren, 1954). Recently, Wilson (1974) argued that stimulus discriminability was an important factor in STM tasks and warned that, despite attempts by experimenters to choose equally discriminable stimuli, some stimulus pairs would be more identifiable than others. The results of the present study and Herzog et al. support this notion in that the animals in both studies showed poorer matching when the choices were between shapes than with color/color choices. In human recognition studies (Potter \& Levy, 1969; Shaffer \& Shiffrin, 1972), presentation time has a significant effect on recall of a series of complex pictures. Conversely, when the item to be remembered was of low information content and thus highly discriminable, such as the position of a dot on a line, Posner and Konick (1966) found no duration effects. Comparable results were reported with pigeons in a matching task by Maki and Leith (1973). They found that, as the number of stimulus dimensions in the sample increased, the sample presentation required for a consistent level of performance increased.

A temporal discrimination model of DMTS performance initially proposed by D'Amato (1973) has received the greatest support in nonhuman primate studies (e.g., Mishkin \& Delacour, 1975; Worsham, 1975). D'Amato noted that the animal's task was to recognize which stimulus was most recently used as a sample. In other words, the DMTS task is a discrimination task, in particular a temporal or recency discrimination. However, the determination of recency requires that a stimulus be identified prior to retrieval of temporal information (Hinrichs, 1970). 
Thus, a temporal discrimination is itself a memorydependent phenomenon (Mason \& Wilson, 1974). Or, as pointed out by Mason and Wilson, the question "What was it?" is not distinct from the question "When was it last seen?" The present data emphasize the importance of the question "What was it?" in that the type of stimulus pairing was a major determinant of DMTS performance. The fact that the discriminability of stimuli influenced matching performance argues against a strict temporal discrimination interpretation of the data. Our results suggest that the determination of recency is but one attribute of memory and that a recency judgment is inevitably confounded with stimuli and their discriminability.

\section{REFERENCE NOTE}

1. Herzog, H. L., Grant, D. S., \& Roberts, W. A. Short-term memory for visual stimuli in the monkey: Effects of presentation time and spaced repetition. Manuscript submitted for publication, 1976.

\section{REFERENCES}

Aaronson, D. Temporal factors in perception and short-term memory. Psychological Bulletin, 1967, 67, 130-144.

D'Aмато, M. R. Delayed matching and short-term memory in monkeys. In G. H. Bower (Ed.), The psychology of learning and motivation: Advances in research and theory (Vol. 7). New York: Academic Press, 1973.

D'Amato, M. R., \& Worsham, R. W. Delayed matching in the capuchin monkey with brief sample duration. Learning and Motivation, 1972, 3, 304-321.

DeviNe, J. V. Stimulus attributes and training procedures in learning-set formation of rhesus and cebus monkeys. Journal of Comparative and Physiological Psychology, 1970, 73, 62-67.

Devine, J. V., \& Jones, L. C. Matching-to-successive samples: A multiple unit memory task with rhesus monkeys. Behavior Research Methods \& Instrumentation, 1975, 7, 438-440.

DRAPER, W. A. Cue dominance in oddity discriminations by rhesus monkeys. Journal of Comparative and Physiological Psychology. 1965, 60, 140-141.

Etkins, M., \& D'Aмato, M. R. Delayed matching-to-sample and short-term memory in the capuchin monkey. Journal of Comparative and Physiological Psychology, 1969, 69, 544-549.
Herman, L. M., \& Gordon, J. A. Auditory delayed matching in the bottlenose dolphin. Journal of the Experimental Analysis of Behavior, 1974, 21, 19-26.

HinRICHS, J. V. A two-process memory-strength theory for judgment of recency. Psychological Review, 1970, 77, 223-233.

Jarrard, L. E., \& Moise, S. L. Short-term memory in the monkey. In L. E. Jarrard (Ed.), Cognitive processes of nonhuman primates. New York: Academic Press, 1971.

MAKI, W. S., \& LEITH, C. R. Shared attention in pigeons. Journal of the Experimental Analysis of Behavior, 1973, 19, 345-349.

Mason, M., \& WILson, M. Temporal differentiation and recognition memory for visual stimuli in rhesus monkeys. Journal of Experimental Psychology, 1974, 103, 383-390.

MelLo, N. K. Alcohol effects on delayed matching to sample performance by rhesus monkey. Physiology and Behavior, 1971, 7, $77 \cdot 101$.

Mishisin, M., \& Delacour, J. An analysis of short-term visual memory in the monkey. Joumal of Experimental Psychology: Animal Behavior Processes, 1975, 1, 326-334.

Peterson, L. R., \& Peterson, M. J. Short-term retention of individual verbal items. Journal of Experimental Psychology, 1959, 58, 193.198.

PosNer, M. I., \& Konick, A. F. On the role of interference in short-term retention. Joumal of Experimental Psychology, 1966. 72, 221-231.

Potter, M. C.. \& Levy, E. I. Recognition memory for a rapid sequence of pictures. Journal of Experimental Psychology, 1969. 81, 10-15.

Roberts, W. A., \& Grant, D. S. Short-term memory in the pigeon with presentation time precisely controlled. Learning and Motivation, 1974, 5, 393-408.

RoHLES, F. H. The development of the instrumental skill sequence in the chimpanzee. Journal of the Experimental Analysis of Behavior, 1961, 4, 323-325.

Shaffer, W. O., \& Shiffrin, R. M. Rehearsal and storage of visual information. Juumal of Experimenial Psychology, 1972. 92. 292-296.

W ARREN, J. M. Additivity of cues in visual pattern discrimination by monkeys. Journal of Comparative and Physiological Psychology, 1954, 46, 484-486.

Wilson, M. Identification, discrimination, and retention of visual stimuli. In A. M. Schrier \& F. Stollnitz (Eds.), Behavior of nonhuman primates: Modern research trends. New York: Academic Press, 1974.

Worsham, R. W. Temporal discrimination factors in the delayed matching-to-sample task in monkeys. Animal Learning \& Behavior, 1975, 3, 93-97.

(Received for publication June 22, 1976; revision accepted September 20, 1976.) 